\title{
Fabrication of Cement, Polymer, and Metal-Matrix Fibre Composites by Gravity-Assisted Liquid-Binder Infiltration: A Practical Approach
}

\author{
Panagiotis Frantzis \\ MIMechE, I. Polyla 13, 54248 Thessaloniki, Greece \\ Correspondence should be addressed to Panagiotis Frantzis, p_frantzis@hotmail.com
}

Received 25 April 2011; Accepted 25 May 2011

Academic Editors: V. Contini, Z. Luo, and Z. Ma

Copyright ( 2011 Panagiotis Frantzis. This is an open access article distributed under the Creative Commons Attribution License, which permits unrestricted use, distribution, and reproduction in any medium, provided the original work is properly cited.

\begin{abstract}
An experimental investigation into the fabrication of cement/polymer/metal fibre composites by gravity-assisted infiltration of the liquid binder is reported. A method was developed consisting of a flow test that was based on columns of woven fibres and an approach that made use of preformed arrays of short fibres to simulate the actual infiltration process. The infiltration characteristics were identified to depend upon the characteristics of the interstice and those of the binders and could be simplified to two key parameters controlling flow: an expression of the fibre interstice and the distance of infiltration. A common relationship was derived between the key parameters. It was concluded that the flow test could be used to assist in the fabrication. A test was also developed that employed a modified binder for the fabrication of fibre reinforced metals. It was concluded that this test was more suitable than others reported in the literature.
\end{abstract}

\section{Introduction}

The use of composite materials in the engineering industry has been rapidly increasing over the last fifty years or so. As a result, the science and technology of composite materials has progressed significantly. Developments in the construction industry include high volume fraction steel fibre reinforced composites fabricated by binder (cement slurry) gravityassisted infiltration into preformed arrays of discontinuous or continuous fibres, known as SIFCON (slurry infiltrated fibre concrete) as reported elsewhere [1-5]. Effective infiltration was shown to be necessary to achieve optimum mechanical properties. It was concluded that understanding of the characteristics of infiltration was essential. Work into the rheological characteristics of magnesium phosphate and ordinary Portland cement binders has also been reported by Frantzis and Baggott $[6,7]$. A relationship was derived, based on experimental observations, between viscosity and setting time that enabled the time available for effective gravity-assisted infiltration to be determined. Developments in the area of fabrication of metal fibre composites include pressureless liquid-binder infiltration techniques for the fabrication of composites with a magnesium-containing aluminium alloy binder reported by Aghajanian et al. $[8,9]$ and Dwivedi et al. [10]. The techniques developed employed preformed arrays of the fibres, contained within refractory vessels, infiltrated by the molten binder to identify, when possible, relationships between distance of infiltration and other process parameters. The results demonstrated the existence of linear relationships among infiltration distance, magnesium content, and process temperature.

The work reported here is a continuation of a large programme of experimental work on the fabrication of composites by gravity-assisted infiltration of (i) high volume fraction short steel fibre reinforced rapid hardening cements reported by Frantzis and Baggott [11], (ii) fabric (woven glass fibres) reinforced polymers with an epoxy resin binder, and (iii) short ceramic fibre reinforced metals with a modified $(10 \% \mathrm{Mg}+1 \% \mathrm{Bi}$ by weight) aluminium alloy binder. The characteristics of the interstices (that define the pore geometry) in arrays of discontinuous steel fibres (an array was regarded as set of fibres in random orientations) through which the binder (cement slurry) flows were considered to be a key parameter determining resistance to flow and 
therefore controlling gravity-assisted infiltration. However, the cost of commercially available short stainless steel fibres is too high and the preparation of arrays time consuming. To overcome these problems, a flow test was developed that was hoped to be able to simulate the flow of the binder through the arrays. The flow test was based on columns of woven stainless steel fibres infiltrated by the magnesium phosphate binder (the plane of the fabric was normal to the direction of flow) to identify possible relationships between interstice characteristics and infiltration distance. The distance of infiltration, considered to depend upon the characteristics of the binder (rheology that included viscosity and setting/curing time, particle size, adhesion to fibres), was thought to be another key parameter of the fabrication process. A semiempirical expression characterising woven steel fibre interstice was identified based on fibre spacing and volume fraction (a measure of porosity), concepts that have proved helpful in explaining composite mechanical behaviour as discussed by Romualdi and Mandel [12], Kar and Pal [13], and Ganeshalingam et al. [14].

Further, an experimental approach was adopted that included a method to provide a measure of the average horizontal and vertical fibre spacing in preformed arrays of short steel fibres (prepared using a steel mould). The approach also included measurement of the infiltration distance, at the level where uniform infiltration had occurred, of the magnesium phosphate into the preformed arrays that was considered to simulate the actual infiltration process involved. The interstice characterisation was extended to include steel fibre arrays. Analysis of the data obtained has established that there was a common relationship between the expression characterising interstice and the distance of infiltration for both types of steel fibres. This indicated that the flow through woven fibres was similar to the flow through arrays, implying that a common mechanism of infiltration was in operation, despite the difference between the fibres. The columns of woven steel fibres were next replaced by columns of woven glass fibres. The columns were infiltrated by a liquid epoxy resin binder. The aim was to assess whether the flow test could provide with an inexpensive technique to assist in the fabrication of fabric- (woven glass fibres) based composites as discussed elsewhere [15-20]. This material is also increasingly used for civil engineering applications as discussed elsewhere [21-25].

This part of the experimental work reported here falls into the category of flow through porous media and there is a large number of work reported in the literature on liquid composite moulding/resin transfer moulding/resin infusion related to polymer composites as discussed elsewhere [2636]. The experimental data obtained here might be correlated to Darcy's [37] equation applied to impregnation of fibre assemblies; the characteristics of the interstices might be quantified in a more consistent manner using tessellation or fractal dimensions as discussed by Summerscales et al. [38]; the interpretation of flow characteristics through clustered porous media might be modelled using the KozenyCarman [39] relationships, all well-established relationships and terminology that have been applied over long periods for both civil engineering and materials processing problems and these were not considered here. Details on processing as well as properties characterization of the fabricated composites were also not considered here. The aim was to produce a material in the laboratory with proven reliability and low cost. The flow test aims to provide with a universal hand lay-up fabrication technique capable of producing fabric-based composites with virtually no areas starved of binder thus eliminating the need to improve moulding conditions, a reliable product at very low cost but no scientific shortcomings. The interstice characterisation was therefore extended to include woven glass fibres. Analysis of the data obtained has established that there was a common relationship between the expression characterising interstice and the distance of infiltration for both binders and type of fibres. This indicated that the flow through woven fibres was similar to the flow through arrays and hence similar to the actual infiltration process involved, implying that a common mechanism of infiltration was in operation (that could be modelled by Darcy's equation but not considered here) despite the difference in the nature between the binders and the much more complex nature of the fibres. It was therefore suggested that the flow test could be used to assist in the fabrication of polymer fibre composites and a technique was subsequently proposed for use in research laboratories. No similar work has been reported in the literature before. Finally, an attempt was made to fabricate small-scale samples of short ceramic fibre reinforced metals. A modified test to the one used in the industry reported by Aghajanian et al. [8] and Dwivedi et al. [10] has therefore been developed based on gravity and employing a magnesium-containing aluminium alloy with the addition of bismuth to increase the fluidity of the binder.

\section{Materials}

All materials used were arbitrarily selected and commercially available. Five (square) apertures (openings) of woven (wave styled) stainless steel fibres were selected, 0.57, 0.81, 1.21, 1.56 , and $2.01 \mathrm{~mm}^{2}$ with fibre diameters $0.26,0.46,0.34$, 0.55 , and $0.80 \mathrm{~mm}$, respectively (an aperture or size of $0.57 \mathrm{~mm}^{2}$ corresponds to horizontal spacing of $0.57 \mathrm{~mm}$ $\times 0.57 \mathrm{~mm}$ ). Stainless steel fibres, 20, 25, and $35 \mathrm{~mm}$ long, kidney-shaped cross-sections of nominal diameters $0.12,0.42$, and $0.50 \mathrm{~mm}$, respectively, were selected. Fabrics (woven E-glass fibres) with apertures $0.65 \times 0.85 \mathrm{~mm}^{2}, 0.65$ $\times 1.83 \mathrm{~mm}^{2}$, and $0.65 \times 2.60 \mathrm{~mm}^{2}$ (the material most commonly used in practice and available at that time) were also selected. The glass fibre dimensions were $0.1 \mathrm{~mm}$ thickness and $1.0 \mathrm{~mm}$ width. The epoxy resin used was a two-part cold cured Araldite range adhesive (used for experimental purposes only) that when mixed with the hardener at a concentration of 5 parts per hundred of resin by weight the curing time at room temperature was 2 hours and 40 minutes approximately. The rapid strengthening cementitious binder (water/cement $=0.17$ ) was a magnesium phosphate (ASR1) with $2 \%$ (by weight) addition of a retarder (sodium tetraborate) to extend the setting time (from 4 minutes to 25 minutes) of the fresh binder. The short ceramic fibres used were in the form of a preform (20\% Saffil in a $\mathrm{SiO}_{2}$ binder) 


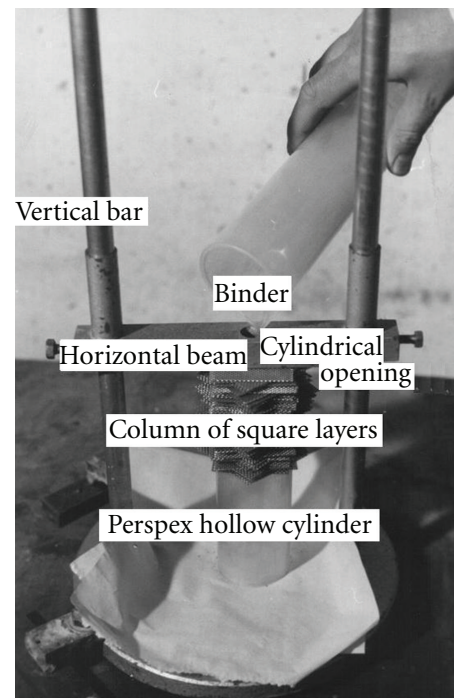

Figure 1: Flow test method apparatus.

and the composition of the aluminium alloy $(9 \%-10 \% \mathrm{Si}$, $0.14 \% \mathrm{Fe}, 0.02 \% \mathrm{Cu}, 0.05 \% \mathrm{Mo}, 0.4 \% \mathrm{Mg}, 0.02 \% \mathrm{Ni}, 0.04 \%$ $\mathrm{Zn}, 0.02 \% \mathrm{~Pb}+\mathrm{Sn}, 0.1 \% \mathrm{Tin}$ ) included the addition of $10 \%$ $\mathrm{Mg}$ by weight.

\section{Methods}

3.1. Flow of Magnesium Phosphate Binder through Columns. A flow test was developed consisting of a column of square layers of woven steel fibres of dimensions $50 \mathrm{~mm}$ by $50 \mathrm{~mm}$ placed approximately at $45^{\circ}$ to each other to simulate more closely the infiltration position, Figure 1 . The column was placed on top of a Perspex hollow cylinder and was kept rigid by the application of moderate (hand) pressure via a horizontal beam as shown. The beam was supported between two vertical bars. The binder was poured through a cylindrical opening (of diameter $14.5 \mathrm{~mm}$ ) at the centre of the horizontal beam to control the amount of binder flowing (a constant rate of fluid) through the column by maintaining a constant head of fluid. The number of layers in the column was varied to give different infiltration distances. The test was stopped shortly after setting time when the binder was trapped between the layers. The layers were carefully removed at the end of each test one by one starting from the bottom and visually examined. In a typical binder flow path, from the first layer to the terminating, the trapped binder could be seen on the upper surface of the terminating layer but there was no binder on the lower surface. The height of the column between the first layer and the terminating, measured by replacing the appropriate number of layers to form a column and using a travelling microscope, provided an accurate measure of infiltration distance. It should be noted that similar flow paths were observed with all apertures used, giving defined measurable infiltration distances, except for the coarsest $\left(2.01 \mathrm{~mm}^{2}\right)$ layers where the binder infiltrated right through the longest practical column that could be set up, detected immediately through the walls of the Perspex cylinder. To estimate the infiltration distance, a further series of tests was carried out with increasing column height noting the time to infiltrate in each case.

3.2. Epoxy Resin. Layers of woven glass fibres replaced the layers of woven steel fibres and a similar procedure was followed. All flow tests gave defined measurable infiltration distances. The tests were stopped shortly after curing time when the flow had been terminated and the binder was trapped between the layers.

3.3. Flow of Magnesium Phosphate Binder through Arrays. An experimental approach was adopted to provide a measure of the average horizontal and vertical fibre spacing in preformed arrays of various steel fibre volume fractions, and including measurement of the infiltration distance of the binder into the arrays. Arrays of fibre volume fractions of $2 \%, 3 \%$, and $5 \%$ were made using the $20 \mathrm{~mm}$ long fibres (it was not possible to prepare arrays of greater fibre volume fraction) and 14\%,15\%, and $16 \%$ and $8 \%, 13 \%$, and $16 \%$ using the $25 \mathrm{~mm}$ and $35 \mathrm{~mm}$ long fibres, respectively. The various arrays of randomly oriented steel fibres were prepared using a steel mould $118 \mathrm{~mm}$ long, $56 \mathrm{~mm}$ deep, and $56 \mathrm{~mm}$ wide. The fibres (were first weighed to give the appropriate fibre volume fraction and then) were dispersed into the mould by hand as evenly as possible. Pressure, applied using a small hydraulic press, was necessary to obtain arrays with higher fibre volume fraction, from 5 up to $16 \%$. Estimates of horizontal spacing were made from photographs of known magnification of the top surface of the arrays. The estimation consisted of characterising horizontal spacing as the side of the equivalent square, formed between fibres, corresponding to the perimeter of the interstice, and subsequent measurement of the side using the travelling microscope. The vertical values of fibre spacing were estimated by observing and thus assuming that fibre orientation in the arrays made using the $20 \mathrm{~mm}$ and $25 \mathrm{~mm}$ long fibres varied between 0 to $45^{\circ}$ to the horizontal. These observations identified vertical spacing to be given by as reported by Romualdi and Mandel [12] and Ganeshalingam et al. [14]:

$$
s_{v}=\frac{s_{h}}{4}+d,
$$

where $s_{v}$ is the vertical fibre spacing, $s_{h}$ the horizontal fibre spacing, and $d$ the fibre diameter. In the case of the arrays made using the $35 \mathrm{~mm}$ long fibres, experimental observations showed that the fibres were almost aligned and thus vertical spacing was assumed to be equal to fibre diameter. Note that it was not possible to obtain clear, sharp, and with good contrast photographs of vertical surfaces. The arrays were infiltrated by the binder, removed from the mould after the binder had hardened, and cut across the centre to enable measurements of the infiltration distance to be made using the travelling microscope. The measurements of the infiltration distance were taken at the level where uniform infiltration had occurred, ignoring 


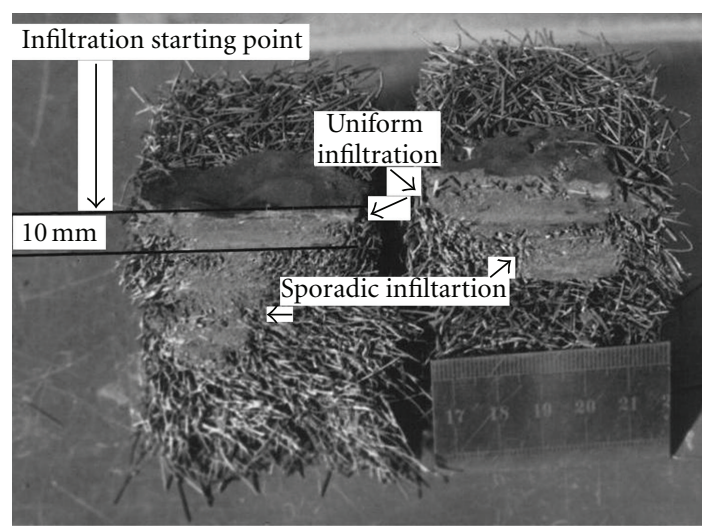

Figure 2: Typical measurements of the infiltration distance in arrays of fibres (sample shown is cut in half) — big arrow indicates starting point and direction of infiltration and small arrows indicate uniform and sporadic infiltration, respectively.

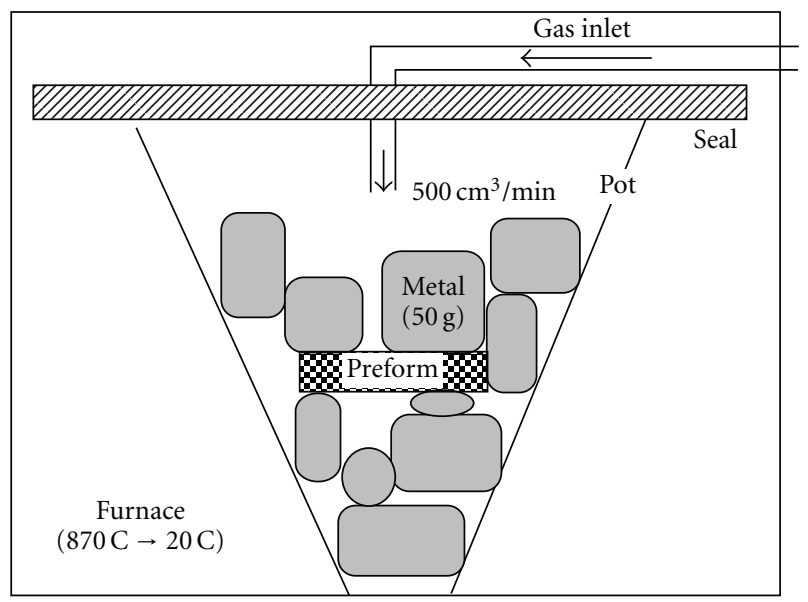

FIGURE 3: Schematic representation of the experimental setup using the modified method of nitrogen-containing gas assisted infiltration.

sporadic infiltration below this level, attributing this to localised regions of lower fibre volume fraction, as Figure 2 shows.

3.4. Aluminium Alloy Binder. Pieces of Al 10\% Mg alloy (about $50 \mathrm{~g}$ ) were placed into a cone-shaped ceramic pot ( $7 \mathrm{~cm}$ height, $4.6 \mathrm{~cm}$ large diameter, $2.3 \mathrm{~cm}$ base diameter, and $0.5 \mathrm{~cm}$ thickness) and the preform was placed either between the metal or on top. The pot was placed in a furnace and a supply of a nitrogen-containing gas (10\% hydrogen-90\% nitrogen) through a ceramic seal at a rate of $500 \mathrm{~cm}^{3} / \mathrm{min}$ was maintained, as Figure 3 shows. 1\% (by weight) of $\mathrm{Bi}$ was also added in some cases either as a solid directly into the pot or as an alloying element in the melt. The furnace, initially at room temperature, was heated to about $870^{\circ} \mathrm{C}$ for 24 hours and then it was switched off and allowed to cool for a further 24 hours. The gas supply was maintained for the 48 hour heating cycle thus ensuring the presence of the gas for the entire fabrication process.
The samples were next removed and prepared for energydispersive X-ray spectroscopy (EDX) and scanning electron microscopy (SEM) examination. This was carried out using a Cambridge 100 Stereo Scan scanning electron microscope at an accelerating voltage of $25 \mathrm{kV}$.

\section{Results and Discussion}

4.1. Flow of Magnesium Phosphate through Columns. Flow of the binder through the columns of woven fibres was assisted by gravity. The $45^{\circ}$ offset in consecutive layers was considered to simulate more closely the infiltration position during composite fabrication. Flow paths were clearly distinguished; they were vertical with no significant lateral divergence producing a cylindrical column of the binder (uniform infiltration), with diameter equal to that of the cylindrical opening at the centre of the horizontal beam. The results of the flow tests using the coarsest $\left(2.01 \mathrm{~mm}^{2}\right)$ layers are presented in graphical form in Figure 4 and show a linear relationship between distance of infiltration (height of column) and time of flow. Extrapolation of the data was necessary and assuming that the infiltration distance could be determined by the setting time of the binder ( 25 minutes) a value of $1122 \mathrm{~mm}$ was identified (Table 1). It was assumed that the distance of infiltration could be related to interstice characteristics; possibly it could be proportional to some function of an interstice expression. To develop an expression it was necessary to establish interstice characteristics. These were considered to be the size, shape, and total volume of the interstices that involved equivalent fibre spacing and volume fraction of the fibres. A semiempirical expression characterising woven fibre interstice was therefore identified based on experience and as reported by Romualdi and Mandel [12] and Ganeshalingam et al. [14] as

$$
\frac{s_{h}^{2} s_{v}}{V_{f}},
$$

where $s_{h}^{2}$ represented the spacing of the square aperture, $s_{v}$ was the spacing between layers (measured using the travelling microscope), and $V_{f}$ the volume fraction of the fibres. This indicated that larger apertures would lead to increasing distance of infiltration, increased vertical spacing would lead to increasing distance, and reduced total volume of space would lead to decreasing infiltration distance. The volume fraction was calculated by considering the volume of the column at the infiltration distance, the density of steel $(7.85 \times$ $10^{3} \mathrm{~kg} / \mathrm{m}^{3}$ ), and the weight of the layers. Table 1 shows the results obtained.

4.2. Flow of Magnesium Phosphate through Arrays. Flow of the binder through the arrays was assisted by gravity. The semiempirical expression characterising woven steel fibre interstice, $s_{h}^{2} s_{v} / V_{f}$, was extended to include steel fibre arrays. The volume fraction was calculated by considering the volume of the mould, the density of steel, and the weight of the fibres. The measurements obtained are shown in Table 2. As expected, the infiltration distance increased with increasing spacing. The apparent discrepancies among 
TABLE 1: Flow test results for magnesium phosphate/woven steel fibres.

\begin{tabular}{lccccc}
\hline $\begin{array}{l}\text { Volume fraction } V_{f} \\
(\%)\end{array}$ & Aperture $s_{h}^{2}\left(\mathrm{~mm}^{2}\right)$ & $\begin{array}{c}\text { Spacing between } \\
\text { layers } s_{v}(\mathrm{~mm})\end{array}$ & $\begin{array}{c}\text { Fibre diameter } d \\
(\mathrm{~mm})\end{array}$ & $\begin{array}{c}\text { Infiltration distance, } \\
h(\mathrm{~mm})\end{array}$ & $s_{h}^{2} s_{v} / V_{f}\left(\mathrm{~mm}^{3} \times 10^{2}\right)$ \\
\hline 26.3 & $0.57 \times 0.57$ & 0.47 & 0.26 & 3.2 & 0.58 \\
26.5 & $0.81 \times 0.81$ & 0.95 & 0.46 & 7.4 & 2.35 \\
20.4 & $1.21 \times 1.21$ & 0.54 & 0.34 & 6.1 & 3.88 \\
23.7 & $1.56 \times 1.56$ & 0.92 & 0.55 & 103.3 & 9.44 \\
21.4 & $2.01 \times 2.01$ & 1.76 & 0.80 & 1122 & 33.2 \\
\hline
\end{tabular}

TABLE 2: Flow test results for magnesium phosphate/steel fibre arrays.

\begin{tabular}{|c|c|c|c|c|c|}
\hline $\begin{array}{l}\text { Volume fraction } V_{f} \\
(\%)\end{array}$ & $\begin{array}{c}\text { Fibre spacing } \\
\text { (horizontal) } s_{h} \\
(\mathrm{~mm})\end{array}$ & $\begin{array}{c}\text { Fibre spacing } \\
\text { (vertical) } s_{v}(\mathrm{~mm})\end{array}$ & $\begin{array}{l}\text { Fibre diameter } d \\
\qquad(\mathrm{~mm})\end{array}$ & $\begin{array}{c}\text { Infiltration } \\
\text { distance } h(\mathrm{~mm})\end{array}$ & $s_{h}^{2} s_{v} / V_{f}\left(\mathrm{~mm}^{3} \times 10^{2}\right)$ \\
\hline 5 & 0.40 & 0.22 & 0.12 & 3.04 & 0.70 \\
\hline 3 & 0.55 & 0.26 & 0.12 & 10.1 & 2.62 \\
\hline 2 & 0.59 & 0.27 & 0.12 & 12.1 & 4.70 \\
\hline 16 & 0.55 & 0.56 & 0.42 & 10.3 & 1.06 \\
\hline 15 & 0.62 & 0.58 & 0.42 & 14.4 & 1.49 \\
\hline 14 & 0.71 & 0.60 & 0.42 & 43.2 & 2.16 \\
\hline 16 & 0.59 & 0.50 & 0.50 & 12.2 & 1.09 \\
\hline 13 & 0.64 & 0.50 & 0.50 & 17.1 & 1.58 \\
\hline 8 & 0.68 & 0.50 & 0.50 & 21.1 & 2.90 \\
\hline
\end{tabular}

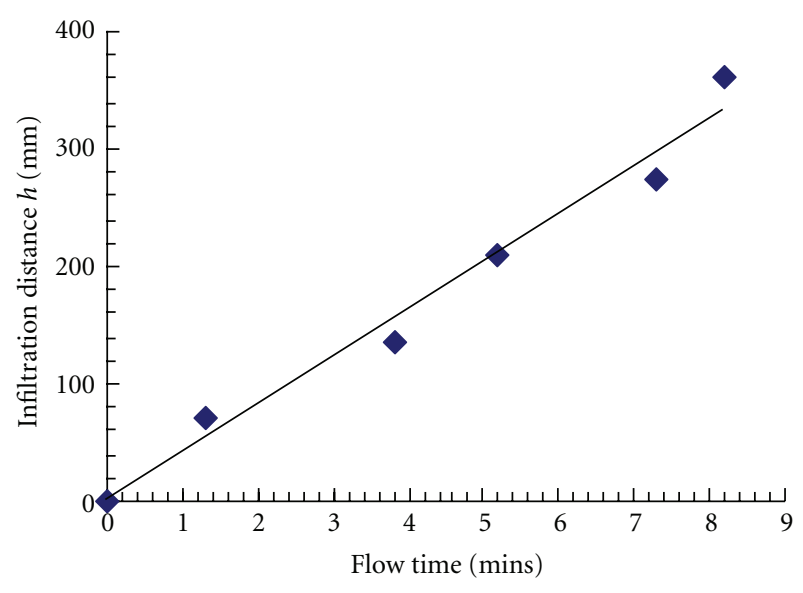

FIGURE 4: Linear relationship between infiltration distance $h$ and flow time.

the infiltration depths observed with the three different lengths of discontinuous fibres shown in Table 2 highlight the importance of characterising the whole interstice. The qualitative explanation of the smaller infiltration depths observed with the $35 \mathrm{~mm}$ long fibres (fibre diameter = $0.5 \mathrm{~mm}$ ), compared with the $25 \mathrm{~mm}$ long fibres (fibre diameter $=0.42 \mathrm{~mm}$ ) at volume fractions less than $14 \%$, being the increased resistance to slurry flow provided by the greater horizontal orientation of the fibres. In the case of the relatively low infiltration with the $20 \mathrm{~mm}$ long fibres (fibre diameter $=0.12 \mathrm{~mm}$ ) the qualitative explanation is that they are significantly finer than the other two fibres and therefore have much reduced vertical spacing.
4.3. Flow of Epoxy Resin through Columns. Flow paths produced a trapezoidal column (truncated cone) of the binder, most probably due to much higher adhesion to glass fibres compared to magnesium phosphate and steel fibres, the big base being on the terminating layer with diameter a maximum four times that of the cylindrical opening at the centre of the horizontal beam. Table 3 shows the results obtained (density of glass $\left.=2.58 \times 10^{3} \mathrm{~kg} / \mathrm{m}^{3}\right)$. The semiempirical expression characterising woven steel fibre interstice, $s_{h}^{2} s_{v} / V f$, was extended to include woven glass fibres. Adopting the assumptions made in this work, the interstice expression was plotted against infiltration distance in logarithmic form. Data obtained using the magnesium phosphate (Tables 1 and 2) were superimposed on the data obtained using the epoxy resin. The plot is shown in Figure 5. A significant number of replicate tests were carried out and the average values are shown (typical scatter between replicates less than 5\%). The sizes of the three glass fabrics (woven E-glass fibres) used in this work are the sizes of the material commonly used in practice. The best curve was fitted through the experimental data points and a common relationship could be identified as

$$
\frac{s_{h}^{2} s_{v}}{V_{f}}=0.3 h^{0.65}
$$

with $R$-squared value of 0.53 , a low but reasonable value bearing in mind the amount and difficulty of the experimental work. This indicated that the flow through columns was similar to the flow through arrays and hence similar to the actual infiltration processes involved. It was concluded that the flow through columns could be used to study the 
TABLe 3: Flow test results for epoxy resin/woven glass fibres.

\begin{tabular}{|c|c|c|c|c|c|}
\hline $\begin{array}{l}\text { Volume fraction } V_{f} \\
(\%)\end{array}$ & Aperture $s_{h}^{2}\left(\mathrm{~mm}^{2}\right)$ & $\begin{array}{l}\text { Spacing between } \\
\text { layers } s_{v}(\mathrm{~mm})\end{array}$ & $\begin{array}{l}\text { Fibre dimension- } \\
\text { sthickness, width } \\
(\mathrm{mm})\end{array}$ & $\begin{array}{c}\text { Infiltration } \\
\text { distance } h(\mathrm{~mm})\end{array}$ & $s_{h}^{2} s_{v} / V_{f}\left(\mathrm{~mm}^{3} \times 10^{2}\right)$ \\
\hline 32.1 & $0.65 \times 0.85$ & 0.10 & $0.1,1.0$ & 10.3 & 0.17 \\
\hline 32.1 & $0.65 \times 0.85$ & 0.12 & $0.1,1.0$ & 10.8 & 0.20 \\
\hline 32.1 & $0.65 \times 0.85$ & 0.11 & $0.1,1.0$ & 10.5 & 0.19 \\
\hline 32.0 & $0.65 \times 1.83$ & 0.11 & $0.1,1.0$ & 13.1 & 0.41 \\
\hline 32.0 & $0.65 \times 1.83$ & 0.10 & $0.1,1.0$ & 12.8 & 0.37 \\
\hline 32.0 & $0.65 \times 1.83$ & 0.12 & $0.1,1.0$ & 13.3 & 0.45 \\
\hline 31.0 & $0.65 \times 2.60$ & 0.12 & $0.1,1.0$ & 16.4 & 0.65 \\
\hline 31.0 & $0.65 \times 2.60$ & 0.10 & $0.1,1.0$ & 15.7 & 0.54 \\
\hline 31.0 & $0.65 \times 2.60$ & 0.11 & $0.1,1.0$ & 16.1 & 0.60 \\
\hline
\end{tabular}

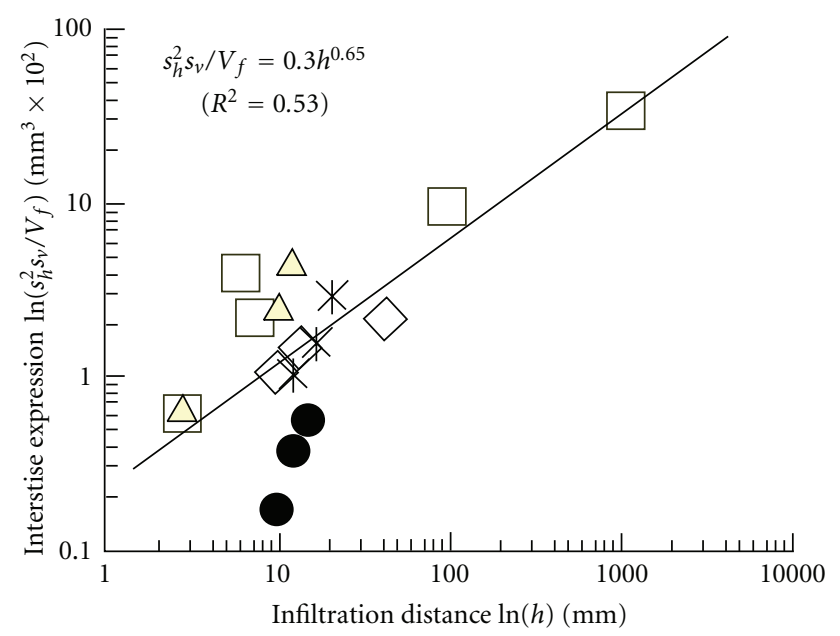

Woven steel fibres

Woven glass fibres

$\triangle 20 \mathrm{~mm}$ discontinuous steel fibres

$\checkmark 25 \mathrm{~mm}$ discontinuous steel fibres

Ж $35 \mathrm{~mm}$ discontinuous steel fibres

FIGURE 5: Logarithmic plot of $\ln \left(s_{h}^{2} s_{v} / V_{f}\right)$ against infiltration distance $\ln (h)$ using columns of woven steel/glass fibres and arrays of steel fibres.

processes involved during composite fabrication, thereby providing a convenient test for the evaluation of likely infiltration characteristics. Hence, having established the applicability and validity of the flow test, Figure 6 was finally plotted that shows the data obtained using the epoxy resin and the glass fibres as a function of the interstice expression $s_{h}^{2} s_{v} / V_{f}$ against infiltration distance $h$. The best curve was fitted through the experimental data points and a linear relationship could be identified as

$$
\frac{s_{h}^{2} s_{v}}{V_{f}}=0.0744 h-0.5854
$$

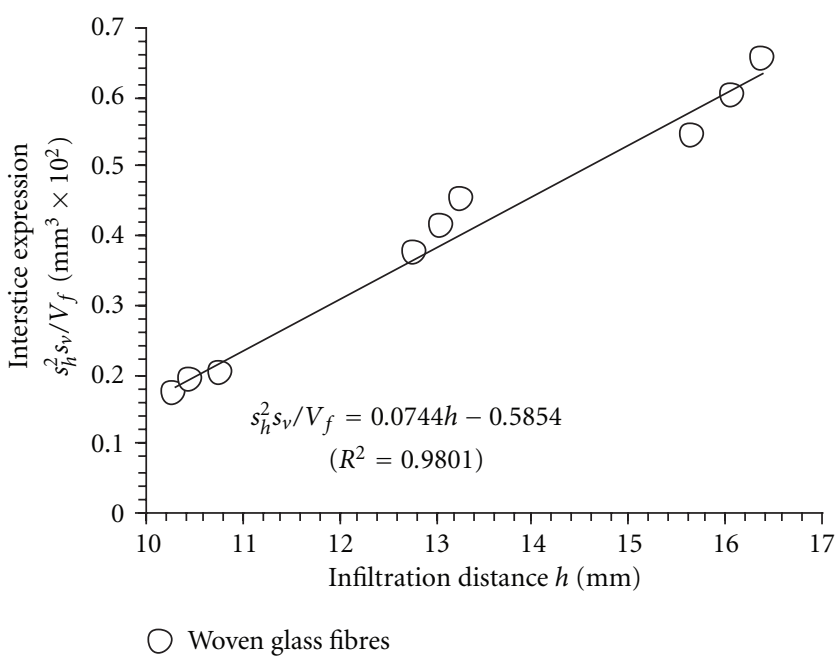

Figure 6: Plot of $s_{h}^{2} s_{v} / V_{f}$ against infiltration distance $h$ for epoxy resin/woven fibres.

with $R$-squared value of 0.9801 indicating a very good fit of the data obtained.

4.4. Fabrication Technique. For the case of polymer composites, a hand lay-up fabrication technique is proposed.

(i) A type of fabric reinforcement (at least three apertures) is acquired. An epoxy resin binder (rapid setting, cold or hot cured) is selected.

(ii) Using the flow test (4) is established and hence the corresponding number of layers for effective infiltration is determined.

(iii) The layers are laid up onto a mould and infiltrated by the binder. After a time interval sufficient for complete infiltration to occur, the product can be fully cured under the simultaneous application of heat and pressure or in air.

(iv) The final product is a polymer laminate (thicknesses between 10 and $16 \mathrm{~mm}$ were achieved here at a fibre volume fraction of $31-32 \%$ ). 
The advantages of the fabrication technique were considered to be as follows.

(i) Any type of fabric material like carbon fibre cloth used in the automotive industry as reported by Cunningham [40] or epoxy resin can be used.

(ii) Less binder waste; virtually no areas starved of binder as reported by Cunningham [41]; only minimal final machining of the edges required to eliminate end effects; minimal technical skills and inexpensive tooling required; no initial investment required.

The disadvantages of the fabrication technique were considered to be

(i) labour intensive; suitable for components of simple or complex shape with fibre volume fraction between $30-40 \%$ (like hulls of boats, roofs of cars, and small unmanned planes).

4.5. Aluminium Alloy Composites. Visual examination (using the travelling microscope) of the samples where the $\mathrm{Bi}$ was not used and the preform was placed on top of the metal showed that the preform was completely intact. Visual examination of the samples where the $\mathrm{Bi}$ was not used and the preform was placed between the metal showed that partial infiltration had occurred (the appearance of each sample was partly white, the colour of the preform, and partly with the colour of the aluminium alloy). Visual examination of the samples where the $\mathrm{Bi}$ was dissolved into the alloy and the preform was placed either on top or between the metal showed that the preform was completely intact and therefore fabrication was not successful. Visual examination of the samples where the $\mathrm{Bi}$ was added as a solid directly into the pot and the preform was placed between the metal showed that complete infiltration had occurred (the appearance of each sample resembled that of the aluminium alloy). The samples in the latter case were next prepared for microscopic examinations as follows: they were cut using a saw, placed in conducting mouldings, ground and polished using colloidal silica polishing suspension and finally washed and dried. Typical SEM images (Figure 7) taken on three points on the cut surfaces showed a fibrous microstructure (black/dark regions) within the aluminium alloy matrix (grey/white regions) at magnifications $50 \mu \mathrm{m}$ and $125 \mu \mathrm{m}$, respectively. Similar results have been reported elsewhere $[8$, 9]. Typical EDX spectrum obtained (Figure 8) taken on three points on the cut surfaces showed strong peaks characteristic of $\mathrm{Mg}, \mathrm{Al}$, and $\mathrm{Si}$ but Bi peak was absent. To provide with a reasonable explanation, either the amount of $\mathrm{Bi}$ was not enough to be detected or the presence of unwanted gases in the furnace chamber might have initiated to reactions that resulted to the failure in detecting Bi which otherwise did not influence the success of the method developed. The results indicated that the addition of Bi can improve fabrication performance and that successful infiltration was obtained only when the Bi was not dissolved into the alloy. The results also indicated that a minimum amount of pressure was still necessary since the weight of the preforms was not enough

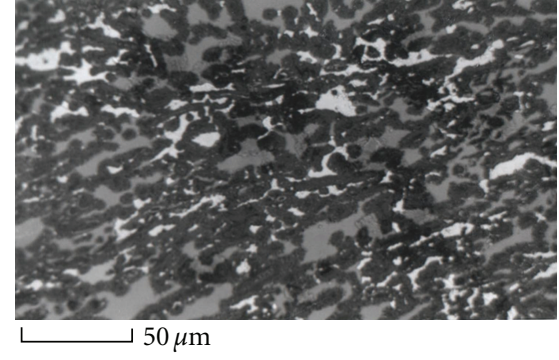

(a)

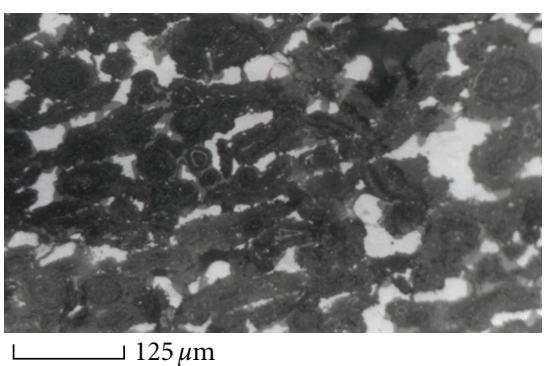

(b)

Figure 7: Typical SEM images of microstructure (preform placed between the metal) for $\mathrm{Al} 10 \% \mathrm{Mg} 1 \% \mathrm{Bi}$ (Bi not dissolved into the alloy) at magnifications $50 \mu \mathrm{m}$ (a) and $125 \mu \mathrm{m}$ (b), respectively, and showing a homogeneous sample.

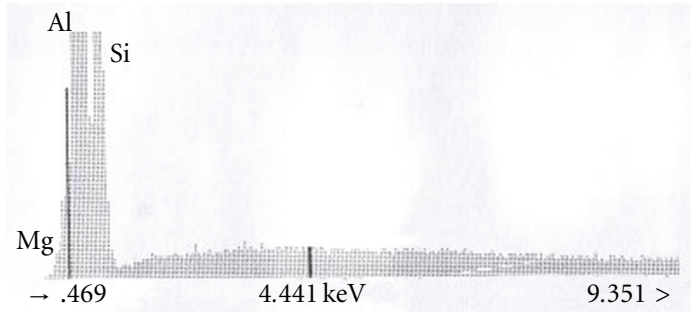

Figure 8: Typical X-ray results for Al 10\% Mg 1\% Bi alloy (Bi not dissolved into the alloy and preform placed between the metal).

for the infiltration process to start by the sinking of the preforms into the melt alloy, as reported in the industry by Aghajanian et al. [8] and Dwivedi et al. [10]. The pressure was a consequence of the weight of the metal above the preforms and therefore this method was thought to be a combination of gas-assisted and gravity-assisted infiltration. Further work is envisaged.

\section{Conclusions}

This paper reports study to fabricate fibre composites by gravity-assisted liquid-binder infiltration into woven fibres and preformed arrays of short fibres. A flow test was developed that was shown to be able to simulate the actual infiltration processes involved during fabrication of cement/polymer fibre composites. A test was also developed that made use of a nitrogen-containing gas and the addition 
of Bi for the fabrication of metal fibre composites. The main findings of this work were therefore as follows.

(1) Flow was identified to depend upon the interstice and the cement/polymer binder characteristics. The characteristics of infiltration were therefore simplified to two key parameters controlling flow: an expression of the interstice through which the binder flows, involving equivalent fibre spacing and volume fraction, and the distance of infiltration.

(2) A common relationship was identified between the key parameters, implying that a common mechanism of infiltration was in operation, despite the difference in the nature between the cement/polymer binders and the much more complex nature of the interstices.

(3) Although the experiments carried out here may at first appear to be basic, the flow test developed has never been reported in the literature before and a hand lay-up technique (of minimal cost and yet sophisticated enough) for the fabrication of polymer composites was subsequently proposed.

(4) The test developed for the fabrication of metal fibre composites may be more attractive than those currently used in the industry because it is relatively simpler and with low cost, at least when intended for use for research purposes.

\section{Acknowledgments}

The financial support of the UK Engineering and Physical Science Research Council is gratefully acknowledged. The writer would also like to thank John Staniar \& Co, Manchester, UK (supplier of woven stainless steel fibres), Fibre Tech Ltd, Nottingham, UK (supplier of stainless steel fibres), Ciba Geigy plc (supplier of epoxy resin), and FEB International, Manchester, UK (supplier of magnesium phosphate ASR1). The author would also like to thank W. J. Cantwell, P. Fox, and G. J. Tatlock for their useful discussions, interest, and support, and D. Whitehurst and M. Hughes for their valuable assistance (University of Liverpool, Liverpool, UK), R. Baggott for his many useful discussions and guidance, and P. B. Unsworth and I. Hanbridge for their valuable assistance (University of Salford, Manchester, UK).

\section{References}

[1] D. R. Lankard and C. Josifek, "SIFCON: slurry infiltrated fibrous concrete," in Proceedings of the Symposium on Fibre Reinforced Concrete, pp. 7.15-7.23, RILEM, Cacham, Cedex, France, 1987.

[2] A. Bentur and S. Mindess, Fibre Reinforced Cementitious Composites, Elsevier Science, London, UK, 1990.

[3] R. Baggott and P. Frantzis, "Pseudo metallic repair materials," in Proceedings of the International Tokyo Symposium on Strategies and Technologies for Maintenance and Modernisation of Building (CIB W70) Part 5: Building Defects and Materials Technology, pp. 527-534, Tokyo, Japan, 1994.
[4] A. M. Brandt, Cement-Based Composites, Materials Mechanical Properties and Performance, E\&FN Spon/Chapman \& Hall, London, UK, 1995.

[5] International Union of Testing and Research Laboratories for Materials and Structures (RILEM), American Concrete Institute (ACI), Centre for Advanced Cement Based Materials (ACBM), the University of Michigan, and the University of Stuttgart, "High performance fiber reinforced cement composites 2 (HPFRCC2)," in Proceedings of the 2nd International RILEM Workshop, RILEM Proceedings 31, A. E. Naaman and H. W. Reinhardt, Eds., E\&FN Spon/Chapman \& Hall, Ann Arbor, Mich, USA, 1996.

[6] P. Frantzis and R. Baggott, "Effect of vibration on the rheological characteristics of magnesia phosphate and ordinary Portland cement slurries," Cement and Concrete Research, vol. 26, no. 3, pp. 387-395, 1996.

[7] P. Frantzis and R. Baggott, "Rheological characteristics of retarded magnesia phosphate cement," Cement and Concrete Research, vol. 27, no. 8, pp. 1155-1166, 1997.

[8] M. K. Aghajanian, M. A. Rocazella, J. T. Burke, and S. D. Keck, "The fabrication of metal matrix composites by a pressureless infiltration technique," Journal of Materials Science, vol. 26, no. 2, pp. 447-454, 1991.

[9] M. K. Aghajanian, R. A. Langensiepen, M. A. Rocazella, J. T. Leighton, and C. A. Andersson, "The effect of particulate loading on the mechanical behaviour of $\mathrm{Al}_{2} \mathrm{O}_{3} / \mathrm{Al}$ metalmatrix composites," Journal of Materials Science, vol. 28, no. 24, pp. 6683-6690, 1993.

[10] R. K. Dwivedi, J. T. Burke, G. H. Shirnky, M. K. Aghajanian, and S. D. Keck, "Flotation process for the formation of metal matrix composite bodies," Patent Number US5529109, 1996.

[11] P. Frantzis and R. Baggott, "Factors influencing magnesia phosphate slurry infiltration into steel fibre arrays," in Proceedings of the International Workshop on Fibre Reinforced Cement and Concrete, R. N. Swamy and V. Ramakrishan, Eds., pp. 4661, National Science Foundation (USA), Centre for Cement and Concrete, University of Sheffield, Sheffield, UK, 1994.

[12] J. P. Romualdi and J. A. Mandel, "Tensile strength of concrete affected by uniformly distributed and closely spaced short lengths of wire reinforcement," Journal of the American Concrete Institute, vol. 61, no. 6, pp. 657-671, 1964.

[13] J. N. Kar and A. K. Pal, "Strength of fibre reinforced concrete," American Society of Civil Engineers [ASCE], Journal of the Structural Division, vol. 98, no. ST5, pp. 1053-1068, 1972.

[14] R. Ganeshalingam, P. Paramasivam, and G. K. Nathan, "An evaluation of theories and a design method of fibre cement composites," International Journal of Cement Composites and Lightweight Concrete, vol. 3, no. 2, pp. 103-114, 1981.

[15] F. L. Matthews and R. D. Rawlings, Composite Materials: Engineering and Science, Chapman \& Hall, London, UK, 1995.

[16] B. T. Åström, Manufacturing of Polymer Composites, Chapman \& Hall, London, UK, 1997.

[17] W. D. Callister Jr., Materials Science and Engineering: An Introduction, John Wiley \& Sons, New York, NY, USA, 4th edition, 1997.

[18] G. Akovali, Handbook of Composite Materials, Rapra Technologies Limited, Shropshire, UK, 2001.

[19] National Physical Laboratory (NPL), SQP Good Practice Guide, Teddington, Middlesex, UK, 2003.

[20] C. Vasile and A. K. Kulshreshtha, Handbook of Polymer Blends and Composites, vol. 1\&2, Rapra Technologies Limited, Shropshire, UK, 2003.

[21] J. M. Illston, Construction Materials, E\&FN Spon, London, UK, 1994. 
[22] Fibreforce Replacing Metals Where It Matters Brochure, Fibreforce Composites Limited, Runcorn, Cheshire, UK, 1997.

[23] S. Wallace, "Design of falls creek trail bridge: a fiber reinforced polymer composite bridge," Transportation Research Record, vol. 1, no. 1652, pp. 133-142, 1999.

[24] D. Greek, "Naval gazing keeps tube ship-shape: a composite material used to patch warships could help keep London's underground train fleet moving too," Professional Engineering Magazine, vol. 13, no. 6, pp. 39-40, 2000.

[25] "Bridge system undergoes tests," Professional Engineering Magazine, vol. 14, no. 20, p. 12, 2001.

[26] V. K. Harten, "Production by resin transfer moulding," in Composite Materials in Maritime Structures, R. A. Shenoi and J. F. Wellicome, Eds., pp. 86-126, Cambridge University Press, Cambridge, UK, 1993.

[27] S. G. Advani and M. V. Bruschke, "Governing equations for flow and heat transfer in stationary fibre beds," in Flow and Rheology in Polymer Composites Manufacturing, S. G. Advani, Ed., pp. 465-515, Elsevier Science, Amsterdam, The Netherlands, 1994.

[28] C. L. Tucker and R. B. Dessenberger, "Resin transfer moulding phenomena in polymeric composites," in Flow and Rheology in Polymer Composites Manufacturing, S. G. Advani, Ed., pp. 257323, Elsevier Science, Amsterdam, The Netherlands, 1994.

[29] C. Williams, J. Summerscales, and S. Grove, "Resin infusion under flexible tooling (RIFT): a review," Composites Part A, vol. 27, no. 7, pp. 517-524, 1996.

[30] K. Potter, Resin Transfer Moulding, Chapman \& Hall, London, UK, 1997.

[31] C. D. Rudd, A. C. Long, K. N. Kendall, and C. G. E. Mangin, Liquid Moulding Technologies, Woodhead Publishing, Cambridge, UK, 1997.

[32] T. M. Kruckenberg and R. Paton, Resin Transfer Moulding for Aerospace Structures, Kluwer Academic Publishers, Dordrecht, The Netherlands, 1998.

[33] D. Cripps, T. J. Searle, and J. Summerscales, "Open mould techniques for thermoset composites," in Comprehensive Composite Materials Encyclopaedia, R. Talreja and J. A. Manson, Eds., vol. 2 of Polymer Matrix Composites, pp. 737-761, Elsevier Science, Oxford, UK, 2000.

[34] R. S. Parnas, Liquid Composite Moulding, Hanser Gardner Publications, 2000.

[35] G. Polaski, J. Means, B. Stull et al., Bonding Elastomers: A Review of Adhesives and Processes, vol. 15, Report 177, Rapra Technologies Limited, Shropshire, UK, 2005.

[36] J. Summerscales and T. J. Searle, "Review: low pressure (vacuum infusion) techniques for moulding large composite structures," in Proceedings of the Institution of Mechanical Engineers (IMechE), Part L, pp. 45-58, Journal of MaterialsDesign and Applications, 2005.

[37] H. P. G. Darcy, Les Fontaines Publiques de la Ville de Dijon, Dalmont, Paris, 1856.

[38] J. Summerscales, F. J. Guild, N. R. L. Pearce, and P. M. Russell, "Voronoi cells, fractal dimensions and fibre composites," Journal of Microscopy, vol. 201, no. 2, pp. 153-162, 2001.

[39] P. C. Carman, "Fluid flow through granular beds," Transactions of the London Institute of Chemical Engineers, vol. 15, pp. 150-166, 1937.

[40] J. Cunningham, "Composites have proved themselves in many ways in specialised industries-so what is holding them back from wider use?" Professional Engineering Magazine, vol. 20, no. 10, pp. 39-40, 2007.
[41] J. Cunningham, "Sum of its parts: how manufacturers are racing to overcome production with composites as demand from the aviation industry begins to soar," Professional Engineering Magazine, vol. 21, no. 10, pp. 28-29, 2008. 

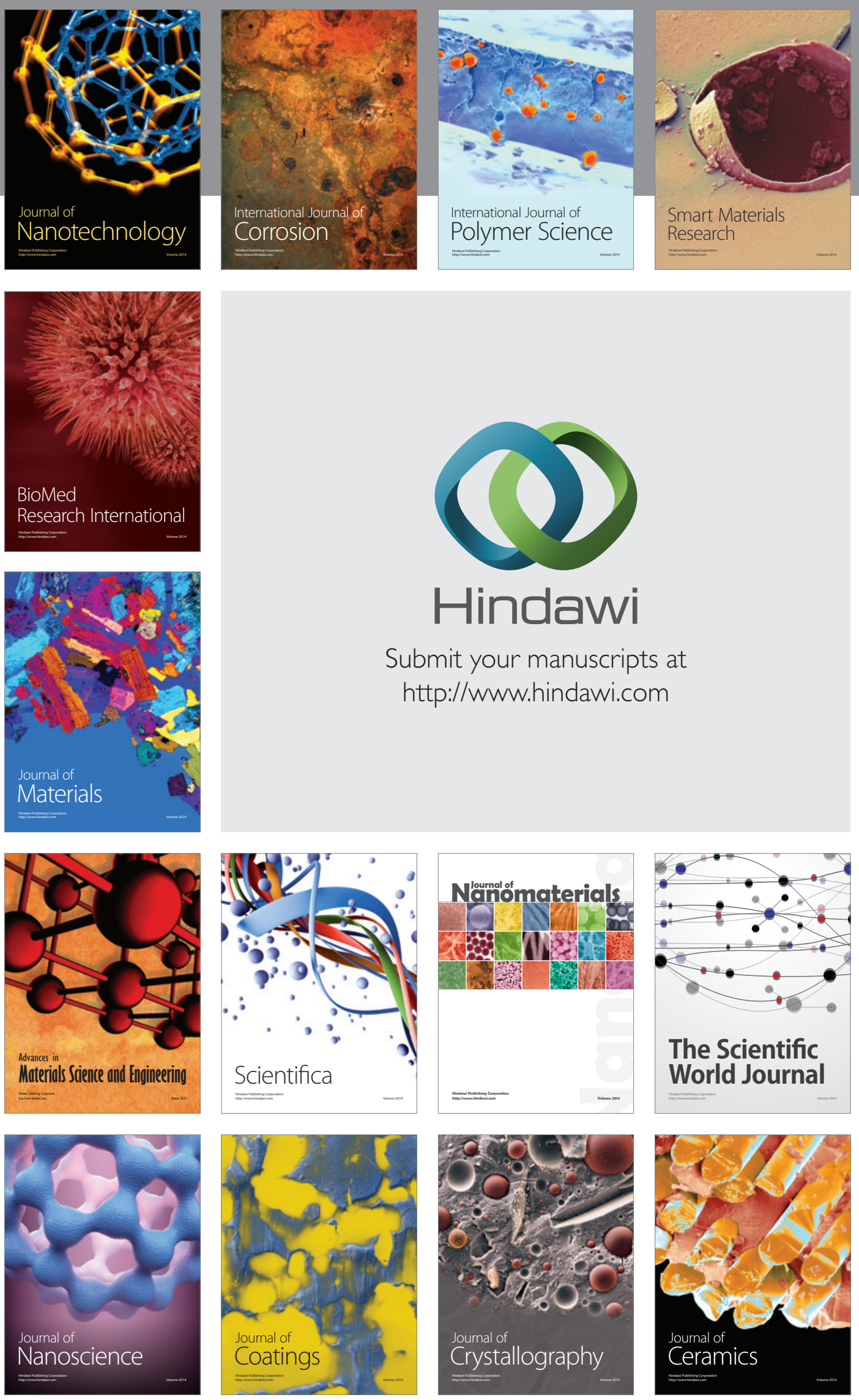

The Scientific World Journal

Submit your manuscripts at

http://www.hindawi.com

\section{World Journal}

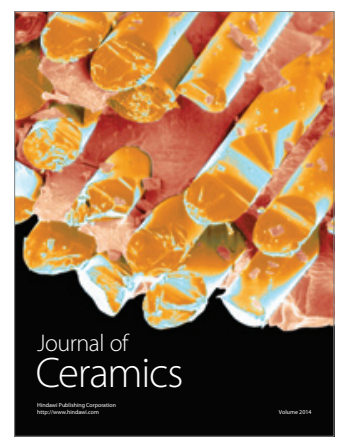

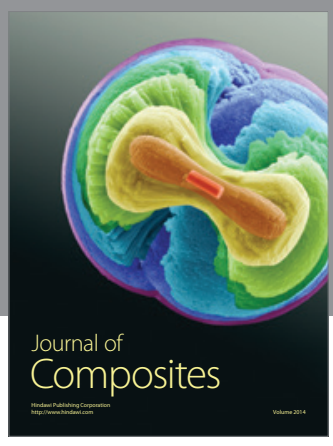
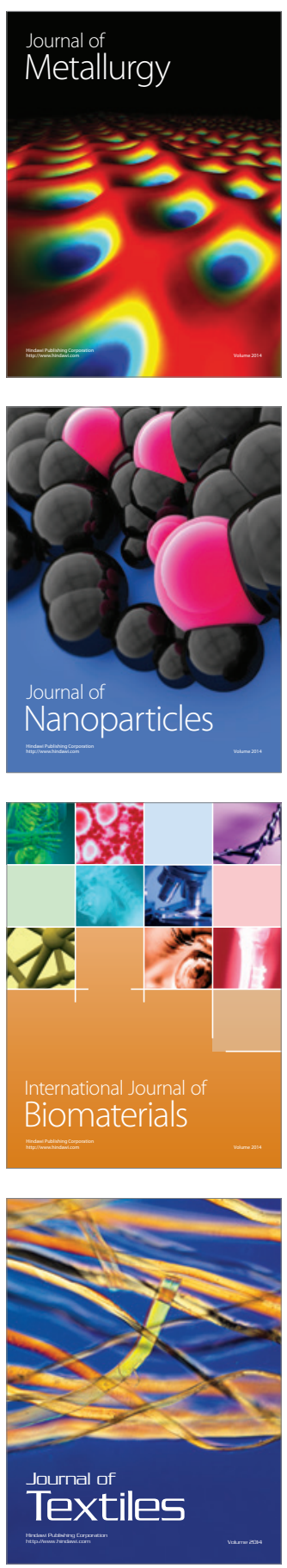